\title{
Correlations between IL-2 Enhancing Activity and Glinical Parameters in Patients with Rheumatoid Arthritis and Systemic Lupus Erythematosus
}

\author{
Kohtaro Tomura, Hoil Kang, Koh Mitamura, Masami \\ Takei, KeiJi Yamagami, Miki Karasaki, Susumu \\ Nishinarita, Takashi Hayama, Shigemasa Sawada and \\ TAKAShI HoRIE
}

The First Department of Internal Medicine, Nihon University School of Medicine, Tokyo 173

\begin{abstract}
Tomura, K., Kang, H., Mitamura, K., Takei, M., Yamagami, K., Karasaki, M., Nishinarita, S., Hayama, T., Sawada, S. and Horie, T. Correlations between IL-2 Enhancing Activity and Clinical Parameters in Patients with Rheumatoid Arthritis and Systemic Lupus Erythematosus. Tohoku J. Exp. Med., 1991, 163 (4), 269-277 — In a previous paper (Tomura, K. et al. Tohoku J. Exp. Med., 1989, 159, 171-183), we discovered IL-2 enhancing factor(s) designated B cell derivedgrowth enhancing factor-2 (BGEF-2), which enhanced IL-2 dependent cell proliferation, and reported that BGEF-2 was produced by $\mathrm{B}$ cells of the patients with rheumatoid arthritis (RA) and systemic lupus erythematosus (SLE) only when they were in the active stage of the disease. In this paper, we studied relationship between each IL-2 enhancing activity from B cell supernatant of the patients with these diseases and clinical parameters. IL-2 enhancing activities did not correlate with erythrocyte sedimentation rate (ESR) and C-reactive protein (CRP), but correlated with plasma concentrations of $\gamma$-globulin from the patients with RA and SLE in the active stages. IL-2 enhancing activities correlated with hypocomplementemia and leukocytopenia in the patients with SLE, and also correlated with RAHA titer in the patients with RA. Moreover, on several patients with RA or SLE in the active stages, diminution of IL-2 enhancing activity was found when they were in the remission stage after treatments. These findings suggested that IL-2 enhancing activity (i.e., BGEF-2 activity) correlated with activity of these diseases and supported the hypothesis that BGEF-2 played an important role in the polyclonal $\mathrm{B}$ cell activation and autoantibody production in patients with these diseases. RA ; SLE ; IL-2 ; B cell
\end{abstract}

Immunological abnormalities such as hypergammaglobulinemia and the production of autoantibodies accompany rheumatic diseases (Decker et al. 1979).

Received October 4, 1990; revision accepted for publication March 20, 1991. Address reprint requests : Shigemasa Sawada, M.D., the First Department of Internal

Medicine, Nihon University School of Medicine, Itabashi-ku, Tokyo 173, Japan.

Supported by Grants-in-Aid from the Ministry of Health and Welfare, Japan. 
Several reports have suggested the possibility that cytokines are involved in the pathogenesis of rheumatic diseases (Morgan and Weigle 1980 ; Muraguchi et al. 1986 ; Romangnani et al. 1986 ; Dobashi et al. 1987). We have recently reported a new lymphokine, IL-2 enhancing factor(s) entitled B cell derived growth enhancing factor(s)-2 (BGFE-2), which enhanced IL-2 dependent proliferation of CTLL A/J cells. BGEF-2 was produced by B cells of the patients with rheumatoid arthritis (RA) and systemic lupus erythematosus (SLE) in the active stages, and had a molecular weight ranging from $15 \mathrm{kd}$ to $20 \mathrm{kd}$, which differed from interleukin (IL)-1, 2, 4, 5, 6, interferon (INF)- $\alpha, \gamma$ and tumor necrosis factor $\alpha(\mathrm{TNF}-\alpha)$ (Tomura et al. 1989).

Here we report the relationship between BGEF-2 activity (i.e., IL-2 enhancing activity from $B$ cell supernatants) of the patients with RA or SLE, and clinical parameters.

\section{Patients and Methods}

\section{Patients}

The group of RA patients consisted of 11 individuals, 6 women and 5 men, aged 27 to 56, all of whom fulfilled the criteria of the American Rheumatism Association (ARA) (Ropes et al. 1958) and included 5 patients in the active stage. All patients with RA were taking nonsteroidal anti-inflammatory drugs or low doses of prednisolone $(2.5$ to $10 \mathrm{mg} / \mathrm{day})$.

The group with SLE consisted of 16 individuals, 10 women and 6 men, aged 15 to 60 , all of whom fulfilled the ARA revised criteria for the classification of SLE (Tan et al. 1982) and included 5 patients in the active stage.

All patients with inactive SLE were taking low doses of prednisolone (2.5 to $10 \mathrm{mg}$ / day). The activity of RA was assessed according to the ARA classification, including the duration of morning stiffness, grasping power, evaluation of the articular index and erythrocyte sedimentation rate. Active SLE was evaluated by the criteria of Budman et al. (1977) as the presence of clinically identifiable active disease (convulsion, serositis, nephritis, arthritis) in at least 1 organ system, not including the skin. All patients were graded as having active or inactive SLE by their attending physician.

The control group consisted of 9 healthy age-matched individuals.

\section{Cell preparation}

Heparinized peripheral blood (about $60 \mathrm{ml}$ ) was treated with silica suspension (KAC-2, Ohtsuka Assay, Tokyo), incubated at $37^{\circ} \mathrm{C}$ for $1 \mathrm{hr}$, and then centrifuged through a lymphocyte separating medium (LSM ; Litton Bionetics, Kensington, England) at 1,500 $\mathrm{rpm}$ for $30 \mathrm{~min}$. The intermediate layer containing lymphocytes was collected, and the cells were washed three times with RPMI 1640 (Irvine Scientific, Santa Ana, CA, USA) medium. These lymphocytes were passed through a G-10 (Pharmasia Fine Chemicals, Sweden) column to remove residual monocytes. Finally these cells were passed through a nylon wool column to obtain B cells and T cells. In brief, 0.5 grams of nylon wool (Wako Pure Chemical Industries, Osaka), and the column was equilibrated with RPMI 1640 medium containing $10 \%$ fetal calf serum (FCS) (M.A. Bioproducts, Walkersville, MA, USA). Four milliliters of cell suspension (1-5 $\times 10^{6}$ cells) was applied to column, and the column was incubated in air with $5 \% \mathrm{CO}_{2}$ at $37^{\circ} \mathrm{C}$ for $1 \mathrm{hr}$ and then washed with approximately $60 \mathrm{ml}$ of RPMI 1640 medium. The passed cells were collected and used as the T cell-enriched fraction.

A fraction enriched with B lymphocytes was recovered from the column by mechanical 
agitation. The nylon wool was removed from the syringe and compressed vigorously in RPMI 1640 medium. T cells remaining (about $30 \%$ ) in the B cells-enriched fraction were removed by cytotoxic treatment with monoclonal anti-Leu-4 antibody (Becton Dickinson, Mountain View, CA, USA) plus rabbit complement, according to the method of Falkoff et al. (1982).

After the removal of $\mathrm{T}$ cells by cytotoxic treatment, the $\mathrm{B}$ cell fraction contained $>$ $94 \%$ B cells, as determined by flow cytometry using a FACS analyzer (Becton Dickinson, Sunnyvale, CA, USA) with FITC-conjugated goat $\mathrm{F}\left(\mathrm{ab}^{\prime}\right)^{2}$ anti-human immunoglobulin (Tago Inc., Burlingame, CA, USA).

\section{Cell culture}

B cells were cultured in microtiterplates at a cell density of $1 \times 10^{6}$ cells $/ \mathrm{ml}$ in RPMI 1640 containing $10 \% \mathrm{FCS}$ in air with $5 \% \mathrm{CO}_{2}$ at $37^{\circ} \mathrm{C}$ for $72 \mathrm{hr}$. RPMI 1640 medium was generally supplemented with $10 \mathrm{mM}$ HEPES, $50 \mathrm{u} / \mathrm{ml}$ penicillin $\mathrm{G}, 50 \mu \mathrm{g} / \mathrm{ml}$ streptomycin and $0.2 \%$ sodium bicarbonate. Each supernatant was obtained as B cell supermatant or $\mathrm{T}$ cell supernatant.

Phytohemagglutinin (PHA) was obtained from Difco Laboratories, Detroit, MI.

\section{$I L$-2-induced proliferation}

IL-2 (Fuji Rebio, Tokyo) was determined by DNA synthesis of the indicator T cell clone, CTLL A/J, according to the method described previously (Kang et al. 1987). Samples serially diluted twofold with RPMI 1640 containing $5 \%$ FCS to $100 \mu \mathrm{l} /$ well. Indicator cells $\left(2 \times 10^{4}\right.$ cells in $100 \mu \mathrm{l}$ of the same medium) were added subsequently and incubated at $37^{\circ} \mathrm{C}$ for $20 \mathrm{hr}$, followed by $4 \mathrm{hr}$ pulse labeling with $0.5 \mu \mathrm{Ci}$ [methyl ${ }^{3} \mathrm{H}$ ] thymidine/well.

Percent effect was calculated by the following equation.

Percent effect $=$

$\frac{(\mathrm{IL}-2(0.5 \mathrm{u} / \mathrm{ml})+\mathrm{B} \text { cell supernatants }(50 \mu \mathrm{l} / \text { well }) \mathrm{cpm}-\mathrm{IL}-2(0.5 \mathrm{u} / \mathrm{ml}) \mathrm{cpm}}{\text { IL-2 }(0.5 \mathrm{U} / \mathrm{ml}) \mathrm{cpm}} \times 100$

One unit/ml of IL-2 induces $50 \%$ of maximum DNA synthesis of $5 \times 10^{4} / \mathrm{ml} \mathrm{CTLL} \mathrm{A/J}$ cells.

\section{RESULTS}

In this paper, we studied the relationship between IL-2 enhancing activity on the proliferation of CTLL A/J cells (i.e., BGEF-2 activity) and clinical parameters.

In the patients with RA, BGEF-2 activity represented $166.4 \pm 137 \%$ in the active stage and $24.9 \pm 6 \%$ in the inactive stage $(p<0.05)$. In the patients with SLE, BGEF-2 activity represented $102.2 \pm 52.2 \%$ in the active stage and $20.6 \pm$ $11.4 \%$ in the inactive stage $(p<0.05)$. In normal volunteers, BGEF-2 activity was represented $16.7 \pm 10.77 \%$ and cut off index $(=\bar{X} \pm 2$ s.D. $)$ was $38.2 \%$. The positivities of BGEF-2 from the patients with RA and SLE were $54.5 \%$ and $43.75 \%$, respectively. These results suggested that BGEF-2 activity had much to do with the activities of these diseases.

We compared BGEF-2 activities with plasma concentrations of $\gamma$-globulin among the patients with RA and SLE. Studies showed a significant relationship between plasma concentrations of $\gamma$-globulin and BGEF-2 activities in those 


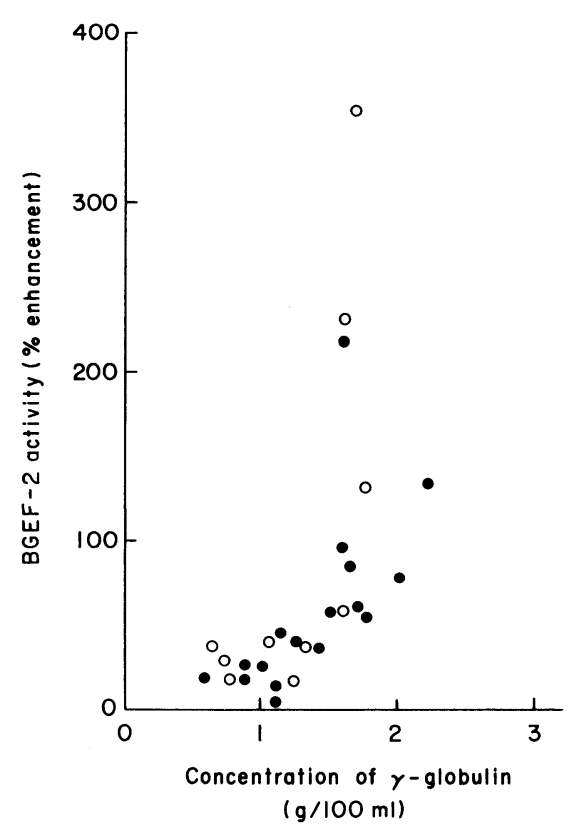

Fig. 1. Relationship between plasma concentration of $\gamma$-globulin and BGEF-2 activity from the patients with $\mathrm{RA}(0)$ and SLE $(\bullet)$. The correlation coefficient, $\gamma$, was 0.49 in the patients with RA, and was 0.48 in the patients with SLE.

patients. The correlation coefficient, $\gamma$, was 0.49 in the patients with RA, and was 0.48 in the patients with SLE (Fig. 1). These results suggested BFEF-2 activity might be associated with polyclonal $\mathrm{B}$ cell activation as a pathogenesis of these diseases.

Next, we compared BGEF-2 activities with RAHA titers in the patients with $\mathrm{RA}$, and with numbers of white blood cell (WBC) and $\mathrm{CH}_{50}$ in the patients with SLE. There was a relationship between serum levels of RAHA and BGEF-2 activities in the patients with RA except for the patients who were sero-negative of RAHA. The correlation coefficient, $\gamma$, was 0.93 (Fig. 2).

There were also inverse relationships between laboratory data such as WBC and $\mathrm{CH}_{50}$, and BGEF-2 activities in the patients with SLE. The correlation coefficient, $\gamma$, was -0.51 in the relationship between WBC and BGEF-2 activities in the patients with SLE.

The correlation coefficient, $\gamma$, was -0.44 in the relationship between $\mathrm{CH}_{50}$ and BGEF-2 activities in those patients (Figs. 3 and 4 ).

These results also suggested that BGEF-2 activity might be implicated in the activities of these diseases. However, no direct correlation was noted between BGEF-2 activities and inflamatory indexes such as erythrocyte sedimentation rate (ESR) and C-reactive protein (CRP) (Fig. 5). 


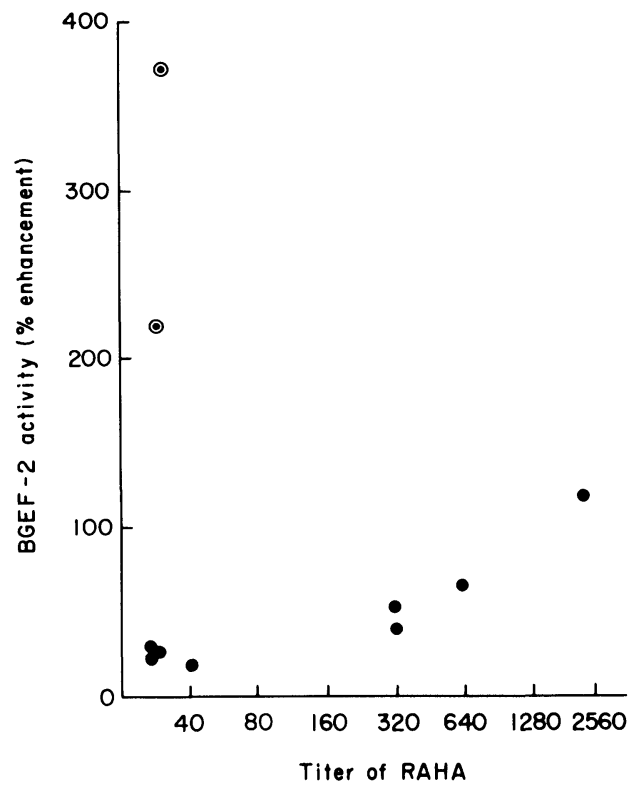

Fig. 2. Relationship between serum level of RAHA and BGEF-2 activity from the patients with $\mathrm{RA}(\bullet)$. There was a reciprocal relationship except for the patients who were sero-negative of RAHA (๑). The correlation coefficient, $\gamma$, was 0.93 .

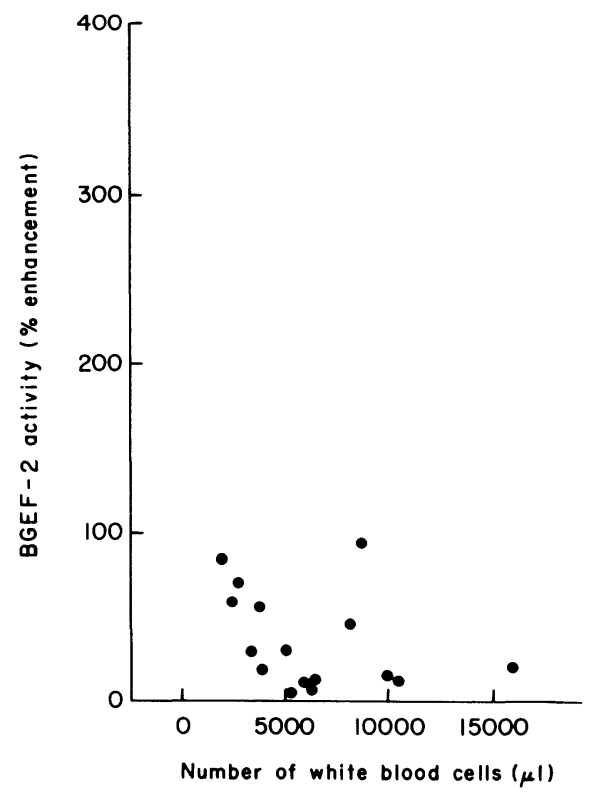

Fig. 3. Relationship between number of white blood cells and BGEF-2 activity from the patients with $\operatorname{SLE}(\bullet)$. There was an inverse relationship and the correlation coefficient, $\gamma$, was -0.51 . 


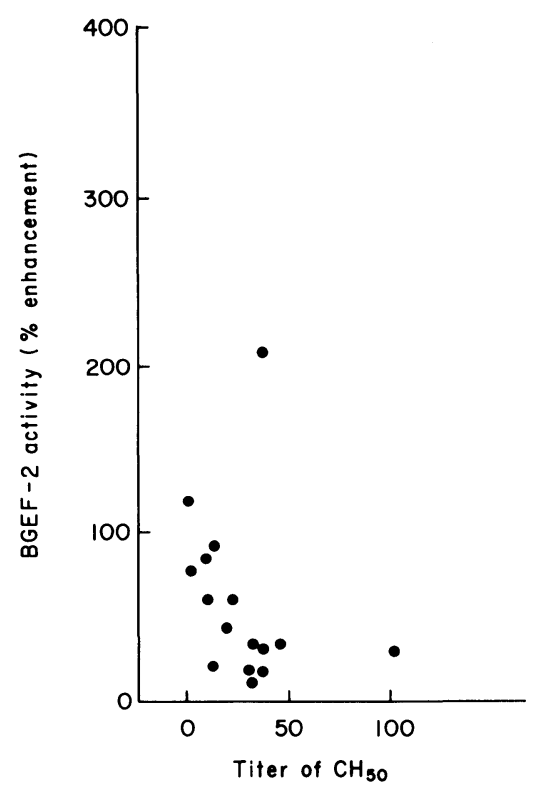

Fig. 4. Relationship between titer of $\mathrm{CH}_{50}$ and BGEF-2 activity from the patients with SLE $(\bullet)$. There was an inverse relationship and the correlation coefficient, $\gamma$, was -0.44 .

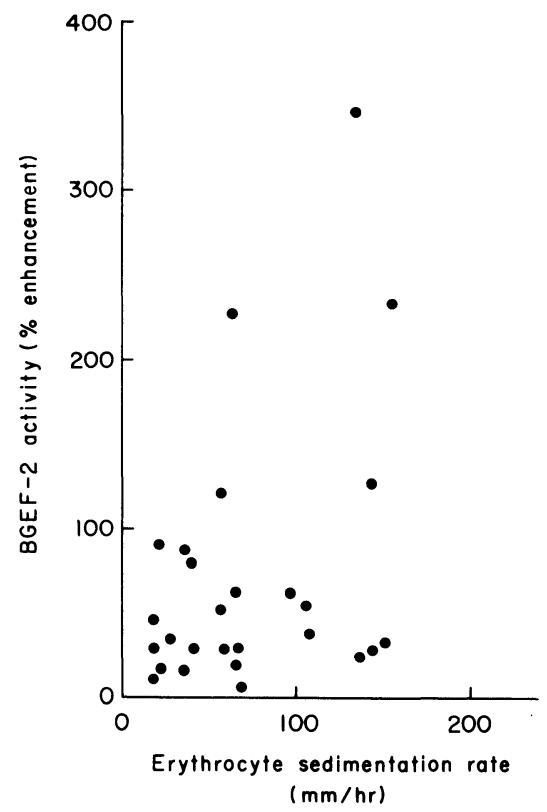

Fig. 5. Relationship between erythrocyte sedimentation rate and BGEF-2 activity from the patients with RA and SLE $(\bullet)$. No direct correlation was noted. 
The observation of the following 3 patients who were positive of BGEF-2 activities revealed that BGEF-2 activities might be concerned with disease activities in the patients with RA and SLE.

Case 1. A 59 year-old man has been suffering from RA since 10 years ago, but was fairly well for past one year. Laboratory findings represented as followed : ESR $76 \mathrm{~mm} / \mathrm{hr}, \mathrm{CRP}(+), \mathrm{RA} 2(+)$, RAHA (-), $\gamma$-globulin $1.35 \mathrm{~g} / 100 \mathrm{ml}$ on July in 1986, and BGEF-2 activity represented $24 \%$. He recognized morning stiffness for half a day and generalized arthralgia on May in 1987. Laboratory findings represented as followed: ESR $97 \mathrm{~mm} / \mathrm{hr}$, CRP $4(+)$. RA $2(+)$, RAHA 640 dils, $\gamma$-globulin $1.84 \mathrm{~g} / 100 \mathrm{ml}$ and BGEF-2 activity represented $61 \%$.

Case 2. A 45 year-old woman with RA began to feel morning stiffness for about $8 \mathrm{hr}$ a day and generalized arthralgia on July in 1986. Laboratory findings represented as followed: ESR $55 \mathrm{~mm} / \mathrm{hr}$, CRP (-), RA $2(+)$, RAHA 320 dils, $\gamma$-globulin $1.50 \mathrm{~g} / 100 \mathrm{ml}$ and BGEF-2 represented $51 \%$.

She was making recovery from morning stiffness and the arthralgia by starting nonsteriodal anti inflammatory agents on February in 1987. Laboratory findings represented as followed: ESR $20 \mathrm{~mm} / \mathrm{hr}, \mathrm{CRP}(-), \mathrm{RA} 2(+), \mathrm{RAHA} 40$ dils, $\gamma$-globulin $1.02 \mathrm{~g} / 100 \mathrm{ml}$ and BGEF-2 activity represented $10 \%$.

Case 3. A 22 year-old woman with SLE was admitted because of her convulsion and pyrexia which diagnosed as central nervous system (CNS) involvement of the disease on November 1986. Laboratory findings represented as followed: ESR $57 \mathrm{~mm} / \mathrm{hr}$, CRP (-), $\gamma$-globulin $2.18 \mathrm{~g} / 100 \mathrm{ml} \mathrm{CH}_{50}<13$, LE (+), ANF 1280 dils, anti DNA antibody 640 dils, IgG $2271 \mathrm{mg} / 100 \mathrm{ml}, \mathrm{IgA} 154 \mathrm{mg} / 100 \mathrm{ml}$, IgM $287 \mathrm{mg} / 100 \mathrm{ml}$, WBC 3700 , and BGEF-2 activity represented $120 \%$.

She was treated with pulse therapy (methylprednisolone $1 \mathrm{~g} /$ day $\times 3$ days) with sympotomatic improvement. Laboratory findings on January in 1987 represented as followed : ESR $12 \mathrm{~mm} / \mathrm{hr}, \mathrm{CRP}(-), \gamma$-globulin $1.38 \mathrm{~g} / 100 \mathrm{ml}, \mathrm{CH}_{50}$ 102, LE (+), ANF 1280 dils, anti DNA antibody 320 dils, IgG 1,765 mg/100 ml, IgA $118 \mathrm{mg} / 100 \mathrm{ml}, \operatorname{IgM} 294 \mathrm{mg} / 100 \mathrm{ml}$, WBC 5500, and BGEF-2 activity represented $32 \%$.

\section{Discussion}

In this paper, BGEF-2 activity was produced by B cells harvested from patients with RA and SLE only in the active stage.

This study provides an additional evidence for the concept that BGEF-2 correlates with clinical and laboratory parameters in the patients with RA and SLE. BGEF-2 activities in the patients with these diseases correlated with plasma concentrations of $\gamma$-globulin, however, did not correlate with inflammatory indexes such as ESR and CRP. We failed to find BGEF-2 activities in the patients with chronic infections such as pulmonary tuberculosis and cholecystitis which represented hypergammaglobulinemia. We also failed to find BGEF-2 activities in the patients with mixed connective tissue disease (MCTD), 
Sjögren syndrome, Behçet disease, malignant lymphoma and B cell-chronic lymphoid leukemia (data not shown). These findings suggested that BGEF-2 activities were specific for the patients with RA and SLE only in the active stage. Though IL-6, as contrast, induces immunoglobulin from B cells and modulates the synthesis of a specific set of acute phase plasma proteins in vivo (Matsuda et al. 1989), BGEF-2 did not correlate with ESR and CRP. These investigations demonstrate the difference between BGEF-2 and IL-6, despite the association with hypergamma globulinemia in the patients with RA and SLE.

A reciprocal relationship between BGEF-2 and RAHA in the patients with $\mathrm{RA}$ and inverse relationships between BGEF-2 and the laboratory parameters such as WBC and complements $\left(\mathrm{CH}_{50}\right)$ in the patients with SLE were observed.

They were indicating that BGEF-2 activity might be a new parameter, which reflected disease activities in the patients with RA and SLE.

Everson et al. (1988) reported IL-2 enhancing factor(s) in murine spleen dendritic cell-T cell culture supernatants. It is unknown whether they are identical to our BGEF-2 or not, but our finding strongly supported their reports. As contrast, we also examined IL-2 suppressing activity on IL-2 dependent T cell proliferation of CTLL A/J cells in B cell supernatants from RA, or SLE in the active stage. But we failed to find out this inhibitory activity by fractionating B cell supernatants from patients with RA or SLE, and normal volunteers.

SLE and RA are an autoimmune disease characterized by hypergammaglobulinemia and high titers of autoandibodies. It has been demonstrated that unstimulated peripheral blood lymphocytes from patients synthesize increased amounts of immunoglobulins (Jasin and Ziff 1975). However, one does not deal with the potential causes of polyclonal B cell activation. Classically, it was thought that polyclonal $\mathrm{B}$ cell activation was due to impaired $\mathrm{T}$ cell regulation. Thus, patient, with SLE may have a defect in suppressor activity for both B cell and $\mathrm{T}$ cell functions (Fauci et al. 1978). The defect in $\mathrm{T}$ cell regulation of $\mathrm{B}$ cell differentiation and proliferation could be responsible for the polyclonal B cell activation. Antilymphocyte antibodies (Budman and Steinberg 1977) demonstrated in patients with active SLE might serve to stimulate lymphocytes to proliferate and differentiate, and thereby give rise to increase in immunoglobulin producing cells. Other causes of excessive B cell stimulation include nonspecific activation of endogenous or exogenous polyclonal B cell activaters such as Epstein Barr virus, lipolysaccharide and staphylococcus aureus Cowan 1. These polyconal B cell activations might let to secrete this BGEF-2 molecule.

The mechanisms triggering the production of BGEF-2 by $\mathrm{B}$ cells and the involvement of BGEF-2 in the pathogenesis of rheumatic diseases are extremely interesting and should be investigated further in other studies.

\section{References}

1) Budman, D.R. \& Steinberg, A.D. (1977) Hematologic aspects of systemic lupus 
erythematosus. Ann. Intern. Med., 86, 220-228.

2) Budman, D.R., Merchant, E.B., Steinberg, A.D., Doft, B., Gershwin, M.E., Lizzio, E. \& Reeves, J.P. (1977) Increased spontaneous activity of antibody - forming cells in the peripheral blood of patients with active SLE. Arthritis Rheum., 20, 829-833.

3) Decker, J.L., Steinberg, A.D., Reinerstein, J.L., Plotz, P.H., Balow, J.E. \& Klippel, J.H. (1979) Systemic lupus erythematosus ; evolving concepts. Ann. Intern. Med., 91, 587-604.

4) Dobashi, K., Ono, S., Murakami, S., Takahama, T., Kottoh, Y. \& Hamaoka, T. (1987) Polyclonal B cell activation by a $\mathrm{B}$ cell differentiation factor B 151-TRF 2III. B 151-TRF 2 as a B cell differentiation factor closely associated with autoimmune disease. J. Immunol., 138, 780-787.

5) Everson, M.P., Tice, S.L. \& Koopman, W.J. (1988) IL-2 enhancing factor a novel T cell factor that specifically enhances IL-2 induced $\mathrm{T}$ cell proliferation. Arthritis Rheum., 31, 18-37.

6) Falkoff, R.J.F., Zhu, L.P. \& Fauci, A.S. (1982) Separate signals for human B cell proliferation and differentiation in response to Staphylococcus aureus; evidence for a two-signal model of B cell activation. J. Immunol., 129, 97-102.

7) Fauci, A.S., Steinberg, A.D., Haynes, B.F. \& Whalen, G. (1978) Immunoregulatory aberrations in systemic lupus erythematosus. J. Immunol., 121, 1473-1479.

8) Jasin, H.E. \& Ziff, M. (1975) Immunoglobulin synthesis by peripheral blood cells in systemic lupus erythematosus. Arthritis Rheum., 18, 219-228.

9) Kang, H., Koyasu, S., Takei, M., Tomura, K., Karasaki, M., Yahara, I. \& Sawada, S. (1987) Characterization of a B cell-derived growth-enhancing factor produced by a human B cell line established from a patient with rheumatoid arthritis. J. Immunol., 139, 1154-1160.

10) Matsuda, T., Hirano, T., Nagasawa, S. \& Kishimoto, T. (1989) Identification of $\alpha_{2}$-macroglobulin as a carrier protein for IL-6. J. Immunol., 142, 148-152.

11) Morgan, E.L. \& Weigle, W.O. (1980) Aggregated human $\gamma$-globulin-induced proliferation and polyclonal activation of murine B lymphocytes. J. Immunol., 125, 226231.

12) Muraguchi, A., Nishimoto, T., Kawamura, H., Hori, A. \& Kishimoto, T. (1986) B cell derived BCGF function as autocrine growth factor(s) in normal and transformed B lymphocytes. J. Immunol., 137, 179-185.

13) Romangnani, S., Giudizi, M.G., Bioagiotti, R., Almerigogna, F., Mingari, C., Maggi, E., Liang, C.M. \& Morreta, L. (1986) B cell growth factor activity of interferon- $\gamma$. Recombinant human interferon- $\gamma$ promotes proliferation of anti- $\mu$-activated human B lymphocytes. J. Immunol., 136, 3513-3516.

14) Ropes, M.W., Bennet, G.A., Caleb, S., Jacox, R. \& Jessar, R.A. (1958) Revision of diagnostic criteria for rheumatoid arthritis. Bull. Rheum. Dis., 9, 175-176.

15) Tan, E.M., Cohen, E.S., Freis, J.F., Masi, A.T., Mesane, D.J., Rothfield, N.F., Schaller, J.G., Talal, N. \& Winchester, R.J. (1982) The 1982 revised criteria for the classification of systemic lupus erythematosus. Arthritis Rheum., 25, 1271-1277.

16) Tomura, K., Kang, H., Mitamura, K., Takei, M., Karasaki, M., Koyasu, S. \& Sawada, S. (1989) IL-2 enhancing factors in B cell supernatants from patients with rheumatoid arthritis or systemic lupus erythematosus. Tohoku J. Exp. Med., 159, 171-183. 